\title{
Influential Indicators and Measurements of Mediating and Moderating Roles on SME Performance
}

Seok-Soo Kim, Hansung University, South Korea

\begin{abstract}
Overcoming the failure of SMEs has been an important research topic. The critical research finding is that it has verified the essential elements of performance improvement. The authors presented a solution to the research question, "Is there a causal relationship between the effect on SMEs' success on capacity and business performance?" They analyzed whether the competence of SMEs had a mediating effect between success variables and performance. Secondary effects were empirically studied by converting independent variables to higher-order component (HOC). The second-order variable of management influenced financial, non-financial, and technical performance, and the second-order variable of technology affected technical performance. As a result of introducing demographic variables as a controlling variable for performance, gender and year of establishment showed a moderating effect on technical and non-financial performance. The authors expect to contribute to practical application to SME CEOs and government policymakers, support organizations, academia, and industry.
\end{abstract}

\section{KEYWORDS}

Influential Indicators, Mediating Effect, Moderating Effect, Performance, SMEs

\section{INTRODUCTION}

Due to the global pandemic of COVID-19 from January 2020, improving the business performance of Small and Medium-sized Enterprises (SMEs) and increasing the survival rate is an essential issue in Korea and the world. In particular, refining influential indicators that can improve performance to activate technology-based SMEs will be academically and practically necessary research. This study began with these research questions and ultimately tried to verify the indicators and measurements of mediating and moderating roles that influence SMEs' performance. To answer these research questions, the purpose of this research is as follows. First, find out and identify the influential indicators in entrepreneurs' capability on competency and performance. Second, empirically prove the effect of SMEs' influential indicators on business performance through competency's mediating effect. Third, empirically verify the impact of competency on business performance. Fourth, using Partial Least Square-Structural Equation Modeling (PLS-SEM), validate the variables affecting the SMEs' performance, and verify causal relationships. Fifth, identifying the degree and difference of demographic variables on performance and providing policymaking results to revitalize SMEs and improve performance. Sixth, applying the Higher-Order Component (HOC) to the five sub-components 
of the capabilities, the independent variable, validates the second-order component's effect on competency and performance. The researcher has been finding out factors and variables, exploring the variables, deriving the key variables, finalizing the research model, and evaluating PLS-SEM. The theoretical research systematically analyzed and organized prior studies related to variables on SMEs' business performance. Literature reviews have identified the disadvantages, problems, and limitations of previous studies. The previous research issues are as follows Entrepreneurs' capabilities can be used as a competitiveness source because competitors do not easily replicate them. Therefore, research has focused on competitiveness and performance (Man et al., 2002; Mitchelmore \& Rowley, 2010). Besides, previous studies have provided a wide range of results investigating the relationship between capabilities and business performance (Hashim et al., 2018). For example, it described that entrepreneurial competency positively impacts its performance (Yusuff et al., 2016). Meanwhile, found a weak relationship between entrepreneurial competency and corporate performance (Narkhede et al., 2014). On the other hand, it found that a company's capabilities do not significantly affect its performance (Lopa \& Bose, 2014). In this context, further research on this relationship is needed (Mitchelmore \& Rowley, 2013). Few empirical studies focused on the link between individual-level competencies and organization-level competitive advantage through potential organization-level mediators. Two recent studies examined the association between entrepreneurial attributes and organizational performance but emphasized the role of corporate activity and performance rather than organizational competency (An et al., 2018; Kantur, 2016; Ng, 2018). To solve previous studies' limitations, revitalize technology-based SMEs, and improve performance, the researcher introduced more complex variables. After reviewing the capability, competency and verified the affection the components on related variables, measurements, and characteristics. By analyzing the influences of variables and confirming the interrelationships, the researcher intended to draw up influential drivers to improve SMEs' performance. According to the six industrial sectors of the Ministry of SMEs and Startups in Korea (Sector 1: electrics/electronics, Sector 2: machinery/parts, Sector 3: IT/SW, Sector 4: chemicals/textiles/materials, Sector 5: life/food, Sector 6: crafts/others), SMEs' influence drivers are not the same. There will be differences, and to verify that there is a difference in the moderating effect according to industries.

\section{BACKGROUND THEORY AND HYPOTHESES}

As researcher looked at the effect of variables on the SMEs' competency and performance:

Found that previous studies have failed to comprehensively research the potential, influential drivers such as management capability, technology capability, network capability, exit strategy, technology commercialization competency, and technical marketing competency. Therefore, the variables studied as influential drivers on competency and performance and the effect of SMEs' competency on performance. The researcher established three hypotheses to verify these research questions. Technology and management capabilities were studied as variables influencing SMEs' innovation capability and competitiveness (Hwang et al., 2020). The research model suggested that technological competence will have a positive (+) effect on SMEs' core competencies (Kim et al., 2020). Six types of variables, according to entrepreneurs, were studied (Prohorovs et al., 2019). The entrepreneurial exit strategies were summarized, and the reason for exit and the option of exit were mentioned (De Tienne, 2010). There were nine hypotheses for motivation causation and effectuation for the entrepreneurial exit strategy (De Tienne et al., 2012, July). The researcher conducted Empirical research on the effect of business commercialization and technological innovation on performance (Bae, et al., 2018). Thus, the Researcher summarized the variables expected to affect the entrepreneur's ability to research sporadically in previous studies and excluded external variables such as entrepreneurship education, government support, and investment. In this research, it was necessary to verify the entrepreneurs' capabilities and technical capabilities as variables that influenced the enterprise's performance, excluding external variables. Therefore, it should be essential to verify the 
impact of SMEs' technological aspects (technical capabilities, commercialization capabilities) and management aspects (management, network, exit strategies) on their competencies. Based on the review, propose the following hypothesis.

Hypothesis 1: Entrepreneurial capability will have a positive effect on competency.

As an independent variable, corporate competencies on SMEs' success and performance were studied (Pauceanu et al., 2019). The dynamic competencies positively impact the business performance of startups (Seo et al., 2019). Practical research on the effect of technology commercialization competency on performance, technological competency, and marketing competency as a moderating variable was studied (Park \& Yang, 2018). An empirical research model on the impact of performance and technology commercialization competency was presented (Bae, et al., 2018). Therefore, it was necessary to verify the effectiveness of competencies that affect performance as mediating variables. It was essential to test the hypothesis that mediate SMEs' variables excluded external matters such as entrepreneurship, government support, and investment. As a mediator of SMEs' performance, excluding external influences, it was necessary to focus and research the technical variables. Therefore, there is a need to verify the performance impact on the technical side. By analyzing the reviews, propose the following hypothesis.

Hypothesis 2: SMEs' competency will have a positive effect on performance.

Studied various ways the effect of SMEs' technology capability on performance. The CEO's experience and career characteristics present as the CEO's technical capabilities among managers' capabilities. Besides, the company's technical capabilities are defined as follows. Technology development capabilities are classified as dedicated technology development organization, professional technical human resources level, technical human resources management, R \& D investment level, the difficulty of imitating possessed technologies, and differentiation from other technologies as technology's uniqueness. Technical performance is defined as the number of patents representing corporate technology's technological effect and its R \& D activity. From a financial point of view, sales, and operating profits used frequently for performance measurement, were used as proxy variables (Lee \& Yang, 2016). Management capability was described, and a research model for the effect of management capability on financial results was studied (Mithas et al., 2011). Knowledge and networks in the global startup process research suggested a network's necessity (Kim \& Bang, 2017). Network competency was studied to moderate manufacturing SMEs' performance (Partanen, et al., 2020). The effect of network competency on technological innovation capability and innovation performance is studied (Englis et al., 2007). Therefore, the influential variables affecting performance are examined from various perspectives. In this research, capability is divided into a management perspective and a technical perspective. In terms of management, it is necessary to categorize it into five sub-variables: management and exit strategy, networkability, technical, and technology commercialization capability, to verify the effectiveness. It is difficult to verify the influential variables affecting improve performance without excluding external variables. As a driver of entrepreneurs' performance, it was necessary to research technology and management capabilities, excluding external influences. Therefore, propose the following hypothesis.

Hypothesis 3: Entrepreneurial capability will have a positive effect on performance.

This research's demographic variables are seven, such as gender, business type, industry sectors, and age. In the previous studies, there were no studies that examined differences in demographic 
Table 1. Explanation of variables

\begin{tabular}{|c|c|c|c|c|}
\hline $\begin{array}{l}\text { Independent } \\
\text { variables }\end{array}$ & $\begin{array}{l}\text { Second-order } \\
\text { components }\end{array}$ & Mediating variables & Dependent variables & $\begin{array}{l}\text { Moderating } \\
\text { variables }\end{array}$ \\
\hline $\begin{array}{l}\text { Management } \\
\text { Capability (MG-C) }\end{array}$ & \multirow{3}{*}{$\begin{array}{l}\text { Management } \\
\text { Capability High } \\
\text { Order (MGC-HO) }\end{array}$} & $\begin{array}{l}\text { Technology } \\
\text { Commercialization } \\
\text { Competency (TC-A) }\end{array}$ & $\begin{array}{l}\text { Financial Performance } \\
\text { (FPF) }\end{array}$ & Gender \\
\hline $\begin{array}{l}\text { Network } \\
\text { Capability } \\
\text { (NW-C) }\end{array}$ & & $\begin{array}{l}\text { Technology Innovation } \\
\text { Competency (TIC-A) }\end{array}$ & $\begin{array}{l}\text { Non-Financial } \\
\text { Performance (NPF) }\end{array}$ & $\begin{array}{l}\text { Type } \\
\text { (private/ corporate) }\end{array}$ \\
\hline $\begin{array}{l}\text { Exit } \\
\text { Capability } \\
(\text { EX-S) }\end{array}$ & & $\begin{array}{l}\text { Technology Marketing } \\
\text { Competency (TM-A) }\end{array}$ & $\begin{array}{l}\text { Technology } \\
\text { Performance } \\
\text { (TECH-P) }\end{array}$ & Production (in/out) \\
\hline $\begin{array}{l}\text { Technology Capability } \\
\text { (TECH-C) }\end{array}$ & \multirow{2}{*}{$\begin{array}{l}\text { Technology } \\
\text { Capability High } \\
\text { Order (TECH-HO) }\end{array}$} & & & Year( 5yr) \\
\hline \multirow[t]{3}{*}{$\begin{array}{l}\text { Technology } \\
\text { Commercialization } \\
\text { Capability (TCC-C) }\end{array}$} & & & & $\begin{array}{l}\text { Division } \\
\text { (6 Industry) }\end{array}$ \\
\hline & & & & $\operatorname{Age}(20 s \sim 50 s)$ \\
\hline & & & & Revenue \\
\hline
\end{tabular}

variables that affect performance. If the difference in demographic variables' performance was verified, it is expected to enhance this research's contribution. Therefore, propose the following hypothesis.

Hypothesis 4: Demographic variables will affect performance, and the degree of impact will vary between the variables.

\section{Research Model and Hypotheses}

\section{Setting Up Research Model}

Our research model tried to answer the following research questions. Do SMEs' capabilities and competencies affect performance? Furthermore, which of them are influential drivers? Which competencies mediating the effect on performance? Do the demographic variables affect and moderate the performance? Moreover, which variables have a moderating effect? It is validating the problems summarized in this research model. First, the independent variable was composed of five sub-variables. Second, the mediator is competency. There are three sub-variables and the dependent variable is performance, and it consists of three sub-variables. The third is to prove the secondary effect, composing five sub-variables of the independent variable into two HOC variables. The fourth is to apply demographic variables to verify if there is a moderating effect on performance.

\section{Completing Research Model}

The research results show using SPSS 22, transforming the research model for selecting measurement variables, setting the secondary effect, and analyzing the moderating effect. The abbreviations for the variables used in our research model shown in Table 1. Figure 1 is the final structural model to verify the moderating effect of demographic variables on the second order's structural model. 


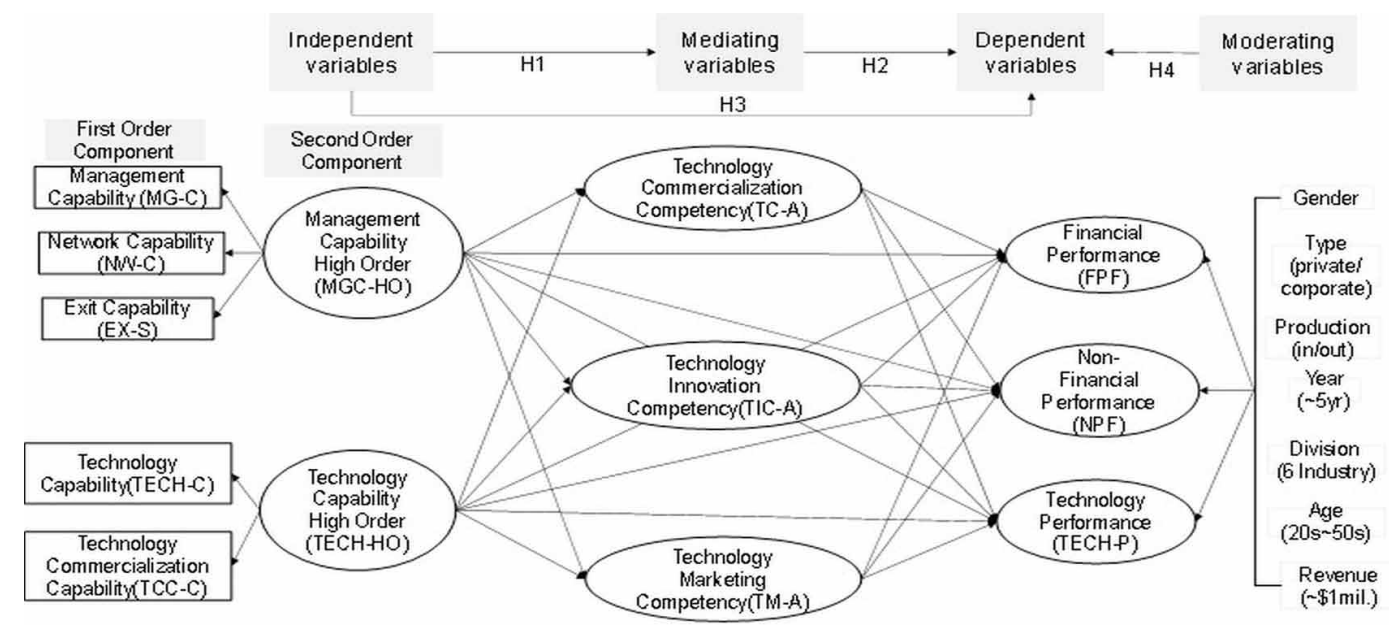

\section{Materials and Method}

The data were collected using an online questionnaire method for 330 CEOs of SMEs based on manufacturing. Response rate was $62.1 \%$ SMEs are less than five years after the startups, and the industrial sector is six fields that defined in Korea SMEs and startups classification criteria: electrics/ electronics, machinery/parts, IT/SW, chemicals/textiles/materials, life/food, crafts/others. Looking at the industry sectors, electrics/electronics $18.5 \%$, machinery/parts $14.8 \%$, IT/SW 17.6\%, chemicals/ textiles/materials $17.6 \%$, life/foods $12.7 \%$, crafts/others $19.0 \%$. The 5-point Likert scale was used to measure the questionnaire. It consists of 77 questions. Statistics of sample shows in Appendix A.

The composition of the questionnaire is as follows. First, questions about the capabilities (number of questions) consist of five sections: management capability (4), technology capability (6), network capability (4), technology commercialization capability (3), exit strategy (3). Second, questions about technology competency. It consist of three sections: 1. technology commercialization competency: development process standardization (4), production management system (5), marketing strategy (5). 2. technological innovation competency: technology development human resources (4), technology accumulation (2), technology innovation system (2), R\&D (2). 3. technology marketing competency: complementary technology (4), core technology (4), product technology (5), process technology (5). Third, questions about performance (number of questions) consist of three sections: technical performance (5), financial performance (5), non-financial performance (5), among the data, insignificant measurement indicators removed through factor analysis. To confirm the reliability and validity required for evaluating the reflective measurement model, the internal consistency reliability, convergent validity, and discriminant validity were assessed using the PLS algorithm. Evaluated the internal consistency reliability by Cronbach's Alpha( $\alpha)$, Dijkstra-Henseler's rho ${ }_{-A}$, and Composite Reliability (CR) Outer loadings, measurement variable reliability, evaluated the convergent validity, Average Variance Extracted (AVE). Using Fornell-Larcker Criterion (FLC), Cross-Loading (CL) to measure and assess discriminant validity in a reflective measurement model (Henseler et al., 2012). Figure 2 shows the methodology flow diagram. Compared to the covariance-based right approach, PLS may be the superior analysis tool due to the minimal demands on measurement scales, sample size, and residual distribution (Wold, 1985). Also, PLS might escape from some fatal problems: inadmissible solutions and factor indeterminacy. 


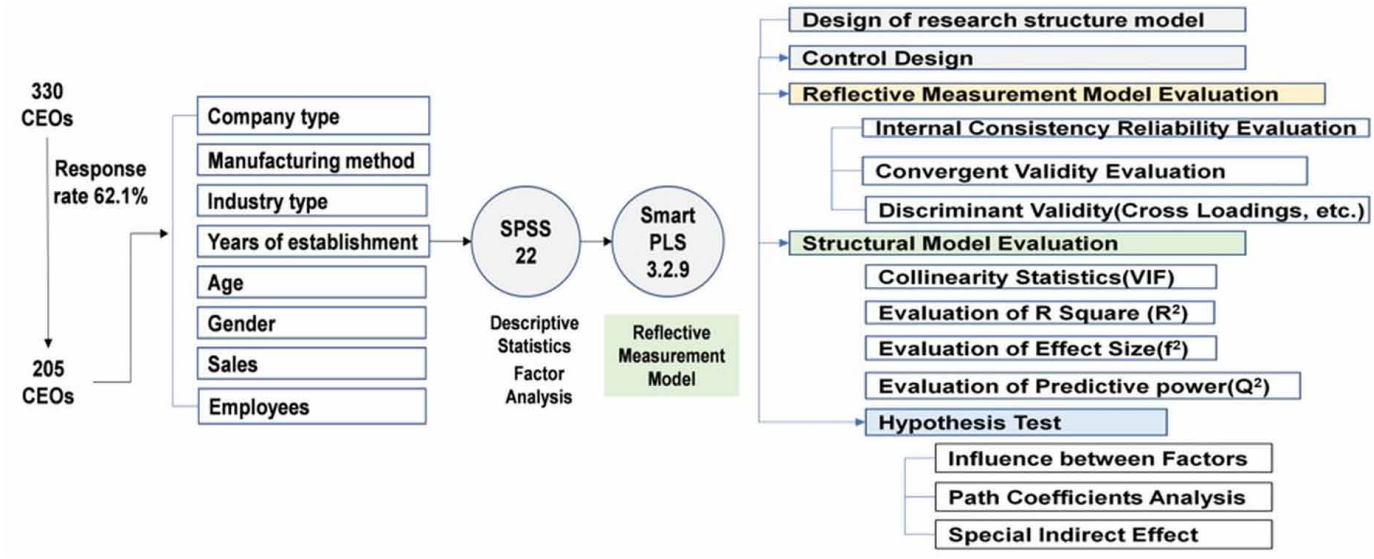

\section{Results}

Research model is a reflective measurement model consisting of reflective indicators. For evaluating the reflective measurement model, Fornell-Larcker Criterion (FLC) was used for outer loading, measurement variable reliability, AVE value, Cronbach's Alpha $(\alpha)$, rho ${ }_{-A}$, CR, and discriminant validity. PLS-SEM performs multicollinearity (Variance Inflation Factor: VIF), coefficient of determination $\left(\mathrm{R}^{2}\right)$, effect size $\left(\mathrm{f}^{2}\right)$, and predictive suitability $\left(\mathrm{Q}^{2}\right)$ by conducting Bootstrapping and Blindfolding to evaluate the structural model and verify the hypotheses. Hypothesis 1 , the entrepreneurial capability will positively affect competency: it proved to be an influential driver for SMEs' performance. Management Capability High Order (MGC-HO) was a robust influential driver on performance. Hypothesis 2, SMEs' competencies will have a positive impact on performance. The Technology Marketing Competency (TM-A) has been a robust driver of financial performance (FPF). It proves to influence performance through the mediating effects of competencies. In hypothesis 3, Entrepreneurial capability will positively affect performance. Only Management Capability High Order (MGC-HO) was a robust influential driver for all three performances. Hypothesis 4, Demographic variables will affect performance, and the degree of impact will vary between the variables; confirmed that year of establishment (YEAR), gender, and company type (TYPE) have a moderating effect on Non-Financial Performance (NPF), and Technology Performance (TECH-P).

\section{Assessment of Measurement Model}

In evaluating the research model's measurement model composed of secondary components, Smart PLS 3.2.9 performed to analyze and assess the internal consistency reliability, convergent validity, and discriminant validity. The PLS algorithm is essentially a regression sequence in the form of a weight vector. The weight vector obtained at convergence satisfies the fixed-point (Hair et al., 2017) and describes the basic PLS algorithm's operation and how implemented in Smart PLS 3.2.9. (Henseler et al., 2012; Ringle et al., 2015). PLS Algorithm execution evaluating the reflective measurement model carried out using the path weighting method, the maximum repetition 1,000 times, and the stopping criterion of $10^{-7}$. Internal consistency reliability was assessed by Cronbach's Alpha, DijkstraHenseler's rho ${ }_{-A}$, and CR. Convergent validity was evaluated by outer loadings, measurement variable reliability, and AVE.

Table 2 shows the results of the PLS algorithm.

As a result of internal consistency reliability evaluation, all of Cronbach's Alpha( $\alpha)$ secured desirable reliability above the threshold of 0.7 . Dijkstra-Henseler's rho ${ }_{-}$was found to have the research variables' internal consistency reliability, all above the threshold of 0.7 . CR all secured 
Table 2. Evaluation of measurement model

\begin{tabular}{|l|c|c|c|c|c|}
\hline & Variable & Cronbach's alpha( $\boldsymbol{\alpha})$ & rho $_{-\mathbf{A}}$ & Composite reliability $^{\text {AVE }}$ \\
\hline \multirow{2}{*}{\begin{tabular}{l}
$2^{\text {nd }} \begin{array}{l}\text { order } \\
\text { component }\end{array}$ \\
\cline { 2 - 6 }
\end{tabular}} & MGC-HO & 0.933 & 0.933 & 0.947 & 0.749 \\
\hline \multirow{4}{*}{$\begin{array}{l}\text { Mediating } \\
\text { variable }\end{array}$} & TECH-HO & 0.915 & 0.918 & 0.933 & 0.665 \\
\cline { 2 - 6 } & TC-A & 0.926 & 0.927 & 0.947 & 0.817 \\
\cline { 2 - 6 } & TM-A & 0.887 & 0.891 & 0.922 & 0.747 \\
\hline \multirow{3}{*}{$\begin{array}{l}\text { Dependent } \\
\text { variable }\end{array}$} & FPF & 0.899 & 0.901 & 0.929 & 0.767 \\
\cline { 2 - 6 } & NPF & 0.851 & 0.852 & 0.930 & 0.870 \\
\cline { 2 - 6 } & TECH-P & 0.855 & 0.858 & 0.932 & 0.873 \\
\hline
\end{tabular}

desirable reliability with a threshold of 0.7 or higher. Convergent validity was assessed by outer loadings, measurement variable reliability, and AVE. The outer loads of the measurement variables were all over the threshold of 0.7 , indicating convergent validity. Outer loadings analysis results show in Table 3. As shown in Table 2, the AVE value, another criterion of the convergent validity, confirmed that the convergent validity was secured. All the measured variables were above the threshold value of 0.5. Fornell-Larcker Criterion (FLC), Cross Loadings (CL), presented as criteria for determining discriminant validity in the reflective measurement model. Since the square root of the AVE of the diagonal is larger than the correlation between the research variables below the diagonal, the research variables' discriminant validity is evaluated. The results show in Table 4. As shown in Table 5, when the reflective measurement model's evaluation results are listed, all evaluation criteria of the reflective measurement model are satisfied. Therefore, this research's measurement model, composed of secondary component variables (MGC-HO, TECH-HO), has reliability and validity.

\section{Second-Order Component Structural Model Evaluation}

This research is evaluated and confirmed the multicollinearity, coefficient of determination $\left(\mathrm{R}^{2}\right)$, and effect size $\left(\mathrm{f}^{2}\right)$ to evaluate PLS-SEM's structural model. The evaluation process is as follows. 1) Evaluate the multicollinearity between research variables. As evaluation criteria for this, internal VIF-values of the structural model (inner model) were used. If the internal VIF-value is less than 5, it evaluated that there is no multicollinearity.

2) Evaluate the explanatory power of exogenous research variables (or predictors, independent variables). As the evaluation criteria for this, the coefficient of determination $\left(R^{2}\right)$ used. If the $R^{2}$ value is 0.25 , it is evaluated as weak explanatory power, 0.5 for medium explanatory power, and 0.75 for strong explanatory power. 3 ) Evaluate the relative influence of exogenous research variables (or predictors, independent variables) on endogenous research variables. In other words, the extent to which exogenous research variables contribute to $\mathrm{R}^{2}$ of endogenous research variables. For this purpose, the effect size $\left(\mathrm{f}^{2}\right)$ was used. If $\mathrm{f}^{2}$ is 0.02 , it is evaluated as a small effect size, 0.15 as a medium effect size, and 0.35 as a significant effect size. 4) Evaluate the significance and suitability of the path coefficients using the t-values calculated by bootstrapping. In conclusion, hypothesis testing was conducted, and Table 6 shows the results of verifying the internal VIF-value by executing the PLS algorithm to confirm multicollinearity. If the inner VIF-values between the latent variables are less than 5, it proved that there is no multicollinearity. As a result, all of them are less than 5, so there is no multicollinearity. Evaluate the explanatory power of exogenous research variables (or predictors, independent variables). As the evaluation criteria for this, the coefficient of determination $\left(\mathrm{R}^{2}\right)$ used. If the $\mathrm{R}^{2}$ value is 0.25 , it is evaluated as weak explanatory power, 0.5 for medium explanatory power, and 
Table 3. Evaluation of measurement model (Outer Loadings)

\begin{tabular}{|c|c|c|c|c|c|c|c|c|c|}
\hline $\mathbf{L} \mathbf{V}^{*}$ & Indicators & $\begin{array}{c}\text { MGC- } \\
\text { HO }\end{array}$ & $\begin{array}{c}\text { TECH- } \\
\text { HO }\end{array}$ & TC-A & TIC-A & TM-A & FPF & NPF & ТЕCH-P \\
\hline \multirow{6}{*}{ MGC-HO } & ES1 & 0.868 & & & & & & & \\
\hline & $\mathrm{ES} 2$ & 0.832 & & & & & & & \\
\hline & MC2 & 0.898 & & & & & & & \\
\hline & MC4 & 0.851 & & & & & & & \\
\hline & NWC3 & 0.849 & & & & & & & \\
\hline & NWC4 & 0.892 & & & & & & & \\
\hline \multirow{7}{*}{$\begin{array}{l}\text { T E C H - } \\
\mathrm{H}\end{array}$} & $\mathrm{TC} 1$ & & 0.815 & & & & & & \\
\hline & TC2 & & 0.868 & & & & & & \\
\hline & TC3 & & 0.862 & & & & & & \\
\hline & TC4 & & 0.865 & & & & & & \\
\hline & TC6 & & 0.817 & & & & & & \\
\hline & TCC1 & & 0.735 & & & & & & \\
\hline & TCC2 & & 0.735 & & & & & & \\
\hline \multirow{4}{*}{$T C-A$} & TCA1 & & & 0.897 & & & & & \\
\hline & TCA3 & & & 0.905 & & & & & \\
\hline & TCA4 & & & 0.902 & & & & & \\
\hline & TCA5 & & & 0.912 & & & & & \\
\hline \multirow{4}{*}{ T I C - A } & TIC10 & & & & 0.882 & & & & \\
\hline & TIC11 & & & & 0.851 & & & & \\
\hline & TIC12 & & & & 0.876 & & & & \\
\hline & TIC3 & & & & 0.848 & & & & \\
\hline \multirow{4}{*}{$\mathrm{T} M-\mathrm{A}$} & TM13 & & & & & 0.851 & & & \\
\hline & TM2 & & & & & 0.890 & & & \\
\hline & TM6 & & & & & 0.879 & & & \\
\hline & TM8 & & & & & 0.882 & & & \\
\hline \multirow{2}{*}{$\mathrm{F} \quad \mathrm{P} \quad \mathrm{F}$} & FP3 & & & & & & 0.930 & & \\
\hline & FP5 & & & & & & 0.936 & & \\
\hline \multirow{2}{*}{$\begin{array}{lll}N & P & F\end{array}$} & NPF1 & & & & & & & 0.939 & \\
\hline & NPF5 & & & & & & & 0.930 & \\
\hline \multirow{3}{*}{ TECH-P } & TP1 & & & & & & & & 0.896 \\
\hline & $\mathrm{TP} 2$ & & & & & & & & 0.810 \\
\hline & TP3 & & & & & & & & 0.897 \\
\hline
\end{tabular}

$\mathrm{LV}^{*}$ : Latent Variable 
Table 4. Evaluation of measurement model (Fornell-Larcker Criterion)

\begin{tabular}{|l|c|c|c|c|c|c|c|c|}
\hline \multicolumn{1}{|c|}{ Latent variable } & FPF & MGC-HO & NPF & TC-A & TECH-HO & TECH-P & TIC-A & TM-A \\
\hline FPF & 0.93 & & & & & & & \\
\hline MGC-HO & 0.78 & 0.86 & & & & & & \\
\hline NPF & 0.84 & 0.82 & 0.93 & & & & & \\
\hline TC-A & 0.70 & 0.78 & 0.79 & 0.90 & & & & \\
\hline TECH-HO & 0.74 & 0.80 & 0.81 & 0.80 & 0.81 & & & \\
\hline TECH-P & 0.79 & 0.84 & 0.84 & 0.81 & 0.86 & 0.86 & & \\
\hline TIC-A & 0.84 & 0.76 & 0.79 & 0.75 & 0.81 & 0.79 & 0.86 & \\
\hline TM-A & 0.80 & 0.77 & 0.79 & 0.76 & 0.79 & 0.85 & 0.80 & 0.87 \\
\hline
\end{tabular}

Table 5. Evaluation of second-order measurement model

\begin{tabular}{|l|c|c|c|c|c|c|}
\hline \multirow{2}{*}{ Latent variable } & \multicolumn{2}{|c|}{ Convergent validity } & \multicolumn{2}{c|}{ Internal consistency reliability } & Discriminant validity \\
\cline { 2 - 7 } & Outer loading & AVE & Cronbach's alpha & rho $_{-\mathbf{A}}$ & CR & Cross loadings \\
\hline MGC-HO & 0.865 & 0.749 & 0.933 & 0.933 & 0.947 & \multicolumn{2}{c|}{ Yes } \\
\hline TECH-HO & 0.814 & 0.665 & 0.915 & 0.918 & 0.933 & Yes \\
\hline TC-A & 0.904 & 0.817 & 0.926 & 0.927 & 0.947 & Yes \\
\hline TIC-A & 0.864 & 0.747 & 0.887 & 0.891 & 0.922 & Yes \\
\hline TM-A & 0.876 & 0.767 & 0.899 & 0.901 & 0.929 & Yes \\
\hline FPF & 0.933 & 0.870 & 0.851 & 0.852 & 0.930 & Yes \\
\hline NPF & 0.935 & 0.873 & 0.855 & 0.858 & 0.932 & Yes \\
\hline TECH-P & 0.868 & 0.755 & 0.836 & 0.838 & 0.902 & Yes \\
\hline
\end{tabular}

Table 6. Multicollinearity evaluation result (Inner VIF-value)

\begin{tabular}{|l|c|c|c|c|c|c|}
\hline & FPF & NPF & TC-A & TECH-P & TIC-A & TM-A \\
\hline MGC-HO & 3.707 & 3.707 & 2.799 & 3.707 & 2.799 & 2.799 \\
\hline TC-A & 3.580 & 3.580 & & 3.580 & & \\
\hline TECH-HO & 4.458 & 4.458 & 2.799 & 4.458 & 2.799 & 2.799 \\
\hline TIC-A & 3.861 & 3.861 & & 3.861 & & \\
\hline TM-A & 3.784 & 3.784 & & 3.784 & & \\
\hline
\end{tabular}

0.75 for strong explanatory power. Evaluate the endogenous variables' explanatory power, the results of confirming the coefficient of determination $\left(\mathrm{R}^{2}\right)$ by executing the PLS algorithm shown in Table 7 .

Evaluate the relative influence of exogenous research variables (or predictors, independent variables) on endogenous research variables, the extent to which exogenous research variables contribute to $\mathrm{R}^{2}$ of endogenous research variables. For this, the effect size $\left(\mathrm{f}^{2}\right)$ was used. If $\mathrm{f}^{2}$ is 0.02 , it is evaluated as a small effect size, 0.15 as a medium effect size, and 0.35 as a large effect size. Table 8 shows the results of confirming the effect size $\left(\mathrm{f}^{2}\right)$. 
Table 7. Evaluation of $\mathbf{R}^{2}$

\begin{tabular}{|l|c|c|}
\hline & R square & Adjusted R square \\
\hline FPF & 0.777 & 0.771 \\
\hline NPF & 0.788 & 0.782 \\
\hline TC-A & 0.698 & 0.695 \\
\hline TECH-P & 0.839 & 0.835 \\
\hline TIC-A & 0.699 & 0.696 \\
\hline TM-A & 0.684 & 0.681 \\
\hline
\end{tabular}

The magnitude of the effect that exogenous research variables contribute to $\mathrm{f}^{2}$ of endogenous research variables is TECH-HO $\rightarrow$ TIC-A $(0.368)>$ TECH-HO $\rightarrow$ TC-A $(0.277)>$ TIC-A $\rightarrow$ FPF $(0.273)>$ TECH-HO $\rightarrow$ TM-A $(0.248)>$ MGC-HO $\rightarrow$ TC-A $(0.185)>$ MGC-HO $\rightarrow$ TM-A $(0.183)>$ $\mathrm{TM}-\mathrm{A} \rightarrow \mathrm{TECH}-\mathrm{P}(0.168)$. All showed an effect size of more than a medium size.

\section{Hypotheses Verification}

Since the structural model's evaluation is appropriate, the hypothesis verification is performed through bootstrapping. The significance and suitability of the route coefficients were evaluated using the t-values calculated by bootstrapping. Through these results, the hypothesis test was conducted. The hypothesis test verified the t-value, $\mathrm{p}$-value, and confidence interval at the significance level of 0.05 . Table 9 shows the results. As a result of arranging the evaluation criteria necessary for the hypothesis verification, as for the influence variables of the secondary component variables, the significant paths that combined the path coefficients, $t$-values, $\mathrm{p}$-values, and confidence intervals $(2.5 \%$ to $97.5 \%)$ values $(\mathrm{p}<0.05)$ are as follows. As a result of hypothesis verification of the effect on the business performance, which is a dependent variable of the secondary component variables aimed at in this research, MGC-HO was found to affect independent variables in three ways: Financial performance $(\mathrm{MGC}-\mathrm{HO} \rightarrow \mathrm{FPF}, \mathrm{p}$-value $=0.008)$, non-financial performance $(\mathrm{MGC}-\mathrm{HO} \rightarrow \mathrm{NPF}$, $\mathrm{p}$-value $=0.000)$ and technical performance $(\mathrm{MGC}-\mathrm{HO} \rightarrow$ TECH-P, $\mathrm{p}$-value $=0.000)$. TECH-HO was found to affect all independent variables, including technical performance (TECH-HO $\rightarrow$ TECH-P, $\mathrm{p}$-value $=0.004)$. As a result of hypothesis verification of the effect on the parameter of the secondary component, MGC-HO was found to affect the parameter in three ways: Technology commercialization capability $(\mathrm{MGC}-\mathrm{HO} \rightarrow \mathrm{TC}-\mathrm{A}, \mathrm{p}-\mathrm{value}=0.000)$, technology innovation capability $(\mathrm{MGC}-\mathrm{HO} \rightarrow \mathrm{TIC}-\mathrm{A}$, $\mathrm{p}$-value $=0.000)$, and technology marketing capability $(\mathrm{MGC}-\mathrm{HO} \rightarrow \mathrm{TM}-\mathrm{A}, \mathrm{p}$-value $=0.000)$. TECHHO was found to affect parameters in three ways: Technology commercialization capability (TECH$\mathrm{HO} \rightarrow \mathrm{TC}-\mathrm{A}, \mathrm{p}$-value $=0.000)$, technology innovation capability $(\mathrm{TECH}-\mathrm{HO} \rightarrow \mathrm{TIC}-\mathrm{A}, \mathrm{p}$-value $=0.000)$, and technology marketing capability $(\mathrm{TECH}-\mathrm{HO} \rightarrow \mathrm{TM}-\mathrm{A}, \mathrm{p}$-value $=0.000)$. Also, it was confirmed

Table 8. Evaluation of effect size $\left(\mathbf{f}^{2}\right)$

\begin{tabular}{|l|l|l|l|l|l|l|}
\hline & FPF & NPF & TC-A & TECH-P & TIC-A & TM-A \\
\hline MGC-HO & 0.084 & 0.125 & 0.185 & 0.144 & 0.122 & 0.183 \\
\hline TC-A & 0.003 & 0.029 & & 0.040 & & \\
\hline TECH-HO & 0.005 & 0.033 & 0.277 & 0.050 & 0.368 & 0.248 \\
\hline TIC-A & 0.273 & 0.039 & & 0.003 & & \\
\hline TM-A & 0.111 & 0.029 & & 0.168 & & \\
\hline
\end{tabular}


Table 9. Hypotheses verification results

\begin{tabular}{|c|c|c|c|c|}
\hline Hypothesis & Path & T statistics & P-value & Significance $(p<0.05)$ \\
\hline \multirow{6}{*}{$\mathrm{H} 1$} & MGC-HO®TC-A & 5.053 & 0.000 & \multirow{14}{*}{ Support } \\
\hline & MGC-HOßTIC-A & 3.634 & 0.000 & \\
\hline & MGC-HO®TM-A & 4.054 & 0.000 & \\
\hline & TECH-HO®TIC-A & 6.08 & 0.000 & \\
\hline & TECH-HO®TM-A & 4.898 & 0.000 & \\
\hline & TECH-HO®TC-A & 5.915 & 0.000 & \\
\hline \multirow{4}{*}{$\mathrm{H} 2$} & TICA®FPF & 4.571 & 0.000 & \\
\hline & TMA®FPF & 3.573 & 0.000 & \\
\hline & TM-A®TECH-P & 3.528 & 0.000 & \\
\hline & TC-A®TECH-P & 2.004 & 0.045 & \\
\hline \multirow{4}{*}{$\mathrm{H} 3$} & MGC-HO®FPF & 2.657 & 0.008 & \\
\hline & MGC-HO®NPF & 3.557 & 0.000 & \\
\hline & MGC-HO®TECH-P & 3.682 & 0.000 & \\
\hline & ТЕCH-HO®ТECH-P & 2.027 & 0.043 & \\
\hline
\end{tabular}

Table 10. Verification of mediating effect

\begin{tabular}{|c|c|c|c|}
\hline Mediating path & T-statistics & P-value & Significance $(p<0.05)$ \\
\hline MGC-HO®TIC-A®FPF & 3.053 & 0.002 & \multirow{6}{*}{ Support } \\
\hline MGC-HO®TM-A®FPF & 2.642 & 0.008 & \\
\hline MGC-HO®TM-A®TECH-P & 2.590 & 0.01 & \\
\hline TECH-HO®TIC-A®FPF & 3.228 & 0.001 & \\
\hline TECH-HO®TM-A®FPF & 2.832 & 0.005 & \\
\hline TECH-HO®TM-А®TECH-P & 2.914 & 0.004 & \\
\hline
\end{tabular}

that the effect on business performance: TC-A affects technical performance (TC-A $\rightarrow$ TECH-P, $\mathrm{p}$-value $=0.045)$, TIC-A affects financial performance $($ TIC-A $\rightarrow F P F, p$-value $=0.000)$, TM-A influences financial performance $(\mathrm{TM}-\mathrm{A} \rightarrow \mathrm{FPF}, \mathrm{p}$-value $=0.000)$, and technical performance $(\mathrm{TM}-\mathrm{A} \rightarrow \mathrm{TECH}-\mathrm{P}$, $\mathrm{p}$-value $=0.000$ ). Bootstrapping performed to check the specific indirect effect (mediation effect) of the competency as a mediator. Table 9 shows the results.

The mediating effects verified by checking the $t$-value, $p$-value, and confidence interval required for hypothesis verification at a significance level of 0.05 . The results show in Table 10. There were four mediating effects on financial performance: $\mathrm{MGC}-\mathrm{HO} \rightarrow \mathrm{TIC}-\mathrm{A} \rightarrow \mathrm{FPF}$ ( $\mathrm{t}$-value $=3.053$, $\mathrm{p}$-value $=0.002)$, TECH-HO $\rightarrow$ TIC-A $\rightarrow$ FPF (t-value $=3.228, \mathrm{p}$-value $=0.001)$, TECH-HO $\rightarrow$ TM-A $\rightarrow$ FPF $(\mathrm{t}$-value $=2.832, \mathrm{p}$-value $=0.005), \mathrm{MGC}-\mathrm{HO} \rightarrow \mathrm{TM}-\mathrm{A} \rightarrow \mathrm{FPF}(\mathrm{t}$-value $=2.642, \mathrm{p}$-value $=0.008)$. The mediating effect on technological performance was found to be significant in two ways: MGC$\mathrm{HO} \rightarrow \mathrm{TM}-\mathrm{A} \rightarrow \mathrm{TECH}-\mathrm{P}(\mathrm{t}-\mathrm{value}=2.590, \mathrm{p}$-value $=0.01), \mathrm{TECH}-\mathrm{HO} \rightarrow \mathrm{TM}-\mathrm{A} \rightarrow \mathrm{TECH}-\mathrm{P}(\mathrm{t}-\mathrm{value}=$ 2.914 , p-value $=0.004)$. Technology Capability High Order $(\mathrm{TECH}-\mathrm{HO})$ was rejected as an influential 
driver for Financial Performance (FPF) and Non-Financial Performance (NPF). The results of Smart PLS Bootstrapping execution for the measurement of the research model and verification of the structural model are summarized in Figure 3.

\section{Moderation Effect Verification}

Figure 3. Result of second-order structural model

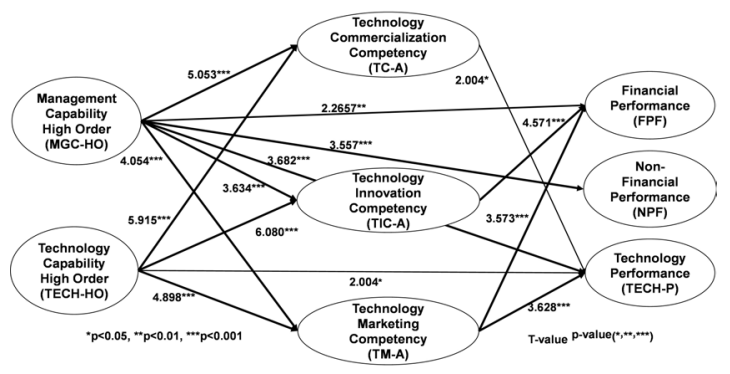

Bootstrapping of Smart PLS 3.2.9 was executed to confirm the moderating effect for each of the three sub-variables of business performance. The primary execution conditions of bootstrapping are as follows. 1) The number of subsamples was set to 5,000 because they are created with randomly extracted (alternate) observations from the original data set. To ensure the stability of the results, the number of subsamples should be more significant. For an initial evaluation, the researcher can use a smaller number of bootstrap subsamples. 2) The resulting range is set to the whole bootstrapping. It will produce all the results available in bootstrapping. Examples include path coefficients, indirect effects, total effects, outer loads, outer weights, coefficients of determination $\left(\mathrm{R}^{2}\right)$, AVE, CR, Cronbach's Alpha( $\alpha$ ). 3) By default, the most stable method, Bias-Correction and Acceleration (BCa) Bootstrap, was used. 4) The verification type was a two-sided test. 5) The significance level was 0.05 . As a result of verification after execution, gender, the company's type, and year showed a significant control effect among the seven variables. Gender had a moderating impact on non-financial performance among the dependent variables, and the path was TECH-HO (secondary component) (B) Gender (moderating variable) $\rightarrow$ NPF (Non-financial performance). Table 10 shows the results. It confirmed that the moderating effect of gender was significant with a path coefficient of 0.176 , a T-statistic value of 2.044, and a p-Value of 0.041 .

Among the dependent variables, the company's type showed a moderating effect on one path to non-financial performance. Furthermore, the path of the significant effect was TECH-HO (an independent variable, and the secondary component) $\rightarrow$ company's type (TYPE) $\rightarrow$ NPF (non-

Table 11. Significant moderating effects

\begin{tabular}{|c|c|c|c|c|}
\hline Hypothesis & Moderating path & T statistics & P-value & Significance $(p<0.05)$ \\
\hline \multirow{5}{*}{$\mathrm{H} 4$} & TECH-HO-GEN®NPF & 2.044 & 0.041 & \multirow{5}{*}{ Support } \\
\hline & TECH-HO-TYPE®NPF & 2.098 & 0.036 & \\
\hline & TECH-HO-YER®NPF & 2.695 & 0.007 & \\
\hline & TC-A-YER®NPF & 2.023 & 0.043 & \\
\hline & TM-A-YER® TECH-P & 2.365 & 0.018 & \\
\hline
\end{tabular}




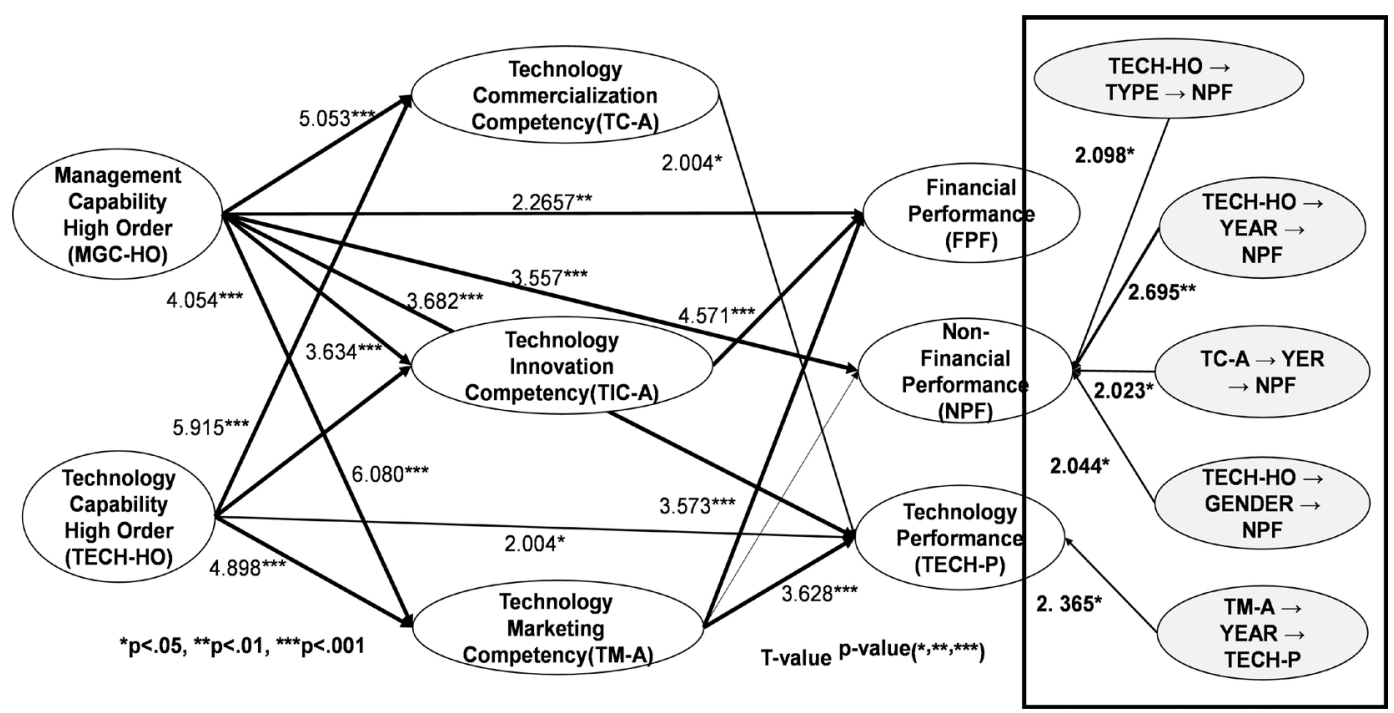

financial performance). It confirmed that the moderating effect on the company type's non-financial performance was significant with a path coefficient of 0.251 , a T-statistic value of 2.098 , and a P-Value of 0.036 . Among the dependent variables, the company's year of establishment has a moderating effect on non-financial performance and technical performance in three ways. The path of the significant effects is TECH-HO $\rightarrow$ YEAR (year of establishment) $\rightarrow$ NPF (non-financial performance), and TC-A (technology commercialization competency) $\rightarrow$ YEAR (year of establishment) $\rightarrow$ NPF (Non-financial performance). The technology marketing competency TM-A (technology marketing competency) $\rightarrow$ YEAR (year of establishment) $\rightarrow$ TECH-P (technology performance). Figure 4 and Table 11 show the results.

\section{Conclusion}

According to the hypothesis test, after performing Algorithm, Bootstrapping, and Blindfolding of Smart PLS3.2.9, the secondary component (MGC-HO) is significant in financial, non-financial, and technical performance at the significance level $<0.05$. Management Capability High Order (MGCHO) was found to be a robust influential driver for all of SMEs' Financial Performance (FPF), Non-Financial Performance (NPF), and Technology Performance (TECH-P). This result proved that the CEO's management ability is essential for SMEs' survival and sustainable growth through performance. Also, Management Capability High Order (MGC-HO) was found to be an influential driver in both the Technology Commercialization Competency (TC-A), Technology Innovation Competency (TIC-A), and Technology Marketing Competency (TM-A). These results proved that the CEO's management ability was essential for strengthening the technological capabilities of SMEs. Technology Capability High Order (TECH-HO) was found to be an influential driver in both the Technology Commercialization Competency (TC-A), Technology Innovation Competency (TIC-A), and Technology Marketing Competency (TM-A). Besides, it was found to be a weak influential driver only in technology performance. However, in the mediating effect, Technology Marketing Competency (TM-A) was a robust influential driver for technology performance by mediating technology capability. The Technology Innovation Competency (TIC-A) was a robust influential driver only for Financial Performance (FPF). Technology Marketing Competency (TM-A) was found to be a robust influential driver for Financial Performance (FPF) and Technology Performance (TECH-P). On the other hand, Technology Commercialization Competency (TC-A) was a weakly influential 
driver for Technology Performance (TECH-P). This result proved that only the Technology Marketing Competency (TM-A) and Technology Innovation Competency (TIC-A) have strong mediating effects on Financial Performance (FPF) and Technology Performance (TECH-P). The verification results of moderating effects confirmed that the company's establishment year has a strong control effect on Non-Financial Performance (NPF) by adjusting the Technology Capability High Order (TECH-HO) $(\mathrm{TECH}-\mathrm{HO} \rightarrow \mathrm{YEAR} \rightarrow \mathrm{NPF})$. Also, it confirmed that the establishment year of the company has a strong control effect on Technology Performance (TECH-P) by adjusting the Technology Marketing Competency (TM-A) (TM-A $\rightarrow$ YEAR $\rightarrow$ TECH-P). It confirmed that there was a weak control effect on Non-Financial Performance (NPF) by adjusting the Technology Innovation Competency (TIC-A) $(\mathrm{TC}-\mathrm{A} \rightarrow \mathrm{YER} \rightarrow \mathrm{NPF}$ ). In the case of Gender, it confirmed that there was a weak control effect on Non-Financial Performance (NPF) by adjusting Technology Capability High Order (TECH-HO) $(\mathrm{TECH}-\mathrm{HO} \rightarrow \mathrm{GEN} \rightarrow \mathrm{NPF}$ ). In the case of type, confirmed that there is a weak control effect on Non-Financial Performance (NPF) by adjusting Technology Capability High Order (TECH-HO) $(\mathrm{TECH}-\mathrm{HO} \rightarrow \mathrm{TYPE} \rightarrow \mathrm{NPF})$.

\section{Contributions and Implications}

The failure of the SMEs' low performance has become a real problem, despite being the basis of the national economy in Korea and worldwide. Nevertheless, governments in each country are prioritizing policies to increase the share of funding. The researcher verified the direct and mediating effects on the influential drivers for enhancing SMEs' business performance and which factors affect performance. Also, demographic variables such as gender, founding year, industry sector, and CEO's age were introduced to verify performance's moderating effect. Although research has validated the results, the following summarizes the areas to be studied by identifying relationships and comparing them to the results. First, the researcher investigates the impact of six emerging technology areas, conducts further research on differentiated performance, and presents more specific and realistic results. Second, further research needs on the technical field, which is subdivided into the technical field's details, and further research will conduct as an advanced research topic following this research. Third, the survey topic was the founders of Korean small and medium enterprises. When only the CEOs of young entrepreneurs were surveyed, practical limitations could not be applied to all possible founders. In the future, the researcher will conduct further research as a research topic to include a wide range of founders, including technology startups from abroad, regional, industrial parks, and industries. The technical disciplines are also grouped into complete frameworks, expanding to manufacturing, nonmanufacturing, IT, S/W, Industry 4.0, digital transformation, electric vehicles, autonomous vehicles, bio-health care, and agriculture. Following this study, the researcher will conduct further research as an in-depth study topic, considering the above considerations.

\section{ACKNOWLEDGMENT}

This paper is included in the HICSS-54 (Knowledge, Innovation, and Entrepreneurial Systems Track). 


\section{REFERENCES}

An, W., Zhang, J., You, C., \& Guo, Z. (2018). Entrepreneur's Creativity and Firm-level Innovation Performance: Bricolage as a Mediator. Technology Analysis and Strategic Management, 30(7), 838-851. doi:10.1080/0953 7325.2017 .1383979

Bae, H. B., Song, M. K., \& Kim, S. G. (2018). A research on the effect of competency of technology startup companies using ETRI technology on management performance. Venture Entrepreneurship Research, 13(1), $61-72$.

DeTienne, D. R. (2010). Entrepreneurial exit as a critical component of the entrepreneurial process: Theoretical development. Journal of Business Venturing, 25(2), 203-215. doi:10.1016/j.jbusvent.2008.05.004

DeTienne, D. R., Chandler, G. N., \& McKelvie, A. (2012, July). The impact of motivation, innovation, and causation and effectuation approaches on exit strategies. In Academy of Management Proceedings (Vol. 2012, No. 1, p. 17155). Briarcliff Manor, NY: Academy of Management. doi:10.5465/AMBPP.2012.17155abstract

Englis, P. D., Wakkee, I., \& Van Der Sijde, P. (2007). Knowledge and networks in the global startup process. International Journal of Knowledge Management Studies, 1(3/4), 497-514. doi:10.1504/IJKMS.2007.012538

Hair, J. F., Hult, G. T. M., Ringle, C. M., Sarstedt, M., \& Thiele, K. O. (2017). Mirror, mirror on the wall: A comparative evaluation of composite-based structural equation modeling methods. Journal of the Academy of Marketing Science, 45(5), 616-632. doi:10.1007/s11747-017-0517-x

Hashim, N. A. B., Raza, S., \& Minai, M. S. (2018). Relationship between Entrepreneurial Competencies and Small Firm Performance: Are Dynamic Capabilities the Missing Link? Academy of Strategic Management Journal, 17(2), 1-10.

Henseler, J., Ringle, C. M., \& Sarstedt, M. (2012). Using partial least squares path modeling in advertising research: basic concepts and recent issues. Handbook of research on international advertising, 252.

Hwang, W. S., Choi, H., \& Shin, J. (2020). A mediating role of innovation capability between entrepreneurial competencies and competitive advantage. Technology Analysis and Strategic Management, 32(1), 1-14. doi:1 $0.1080 / 09537325.2019 .1632430$

Kantur, D. (2016). Strategic Entrepreneurship: Mediating the Entrepreneurial Orientation-performance Link. Management Decision, 54(1), 24-43. doi:10.1108/MD-11-2014-0660

Kim, J., Cho, J., \& Lee, S. (2020). The Influence of Entrepreneurial Competences on Corporate Performance of Technology-based Startups. Journal of the Industrial Management System, 43(1), 132-142.

Kim, J. Y., \& Bang, H. Y. (2017). The Effects of Environmental Uncertainty on the Impact Strategy and Performance of Korean, US, and Japanese Firms: Focusing on Environmental Uncertainty in the Competition Sector. Korean Journal of Trade and Commerce, 17(4), 135-156.

Lee, I. K., \& Yang, D. W. (2016). An Empirical Research on the Effect of CEO Technological Capability on Management Performances: Focusing on mediating effect technological capability in SMEs. Asia-Pacific Journal of Business Venturing and Entrepreneurship, 11(2), 167-182. doi:10.16972/apjbve.11.2.201604.167

Lopa, N. Z., \& Bose, T. K. (2014). Relationship between Entrepreneurial Competencies of SME Owners/Managers and Firm Performance: A Research on Manufacturing SMEs in Khulna City. Journal of Entrepreneurship and Management, 3(3), 1-12.

Man, T. W., Lau, T., \& Chan, K. F. (2002). The competitiveness of small and medium enterprises: A conceptualization with focus on entrepreneurial competencies. Journal of Business Venturing, 17(2), $123-142$. doi:10.1016/S0883-9026(00)00058-6

Mitchelmore, S., \& Rowley, J. (2010). Entrepreneurial Competencies: A Literature Review and Development Agenda. International Journal of Entrepreneurial Behaviour \& Research, 16(2), 92-111. doi:10.1108/13552551011026995

Mitchelmore, S., \& Rowley, J. (2013). Entrepreneurial Competencies of Women Entrepreneurs Pursuing Business Growth. Journal of Small Business and Enterprise Development, 20(1), 125-142. doi:10.1108/14626001311298448 
Mithas, S., Ramasubbu, N., \& Sambamurthy, V. (2011). How information management capability influences firm performance. Management Information Systems Quarterly, 35(1), 237-256. doi:10.2307/23043496

Narkhede, B. E., Nehete, R. S., Raut, R. D., \& Mahajan, S. K. (2014). Impact of Entrepreneurial Skills on the Firm's Performance: Evidence from Manufacturing SMEs in India. International Journal of Indian Culture and Business Management, 8(2), 216-236. doi:10.1504/IJICBM.2014.059207

Ng, H. S., \& Kee, D. M. H. (2018). The Core Competence of Successful Owner-managed SMEs. Management Decision, 56(1), 252-272. doi:10.1108/MD-12-2016-0877

Park, H. G., \& Yang, D. W. (2018). An Empirical Research on the Effect of the Technological Commercialization Ability of the Initial Entrepreneurship on Management Performance: Focusing on the Moderating Effect of Technology entrepreneurs in Manufacturing Industries. Journal of the Korean Entrepreneurship Society, 1(1), 14.

Partanen, J., Kohtamäki, M., Patel, P. C., \& Parida, V. (2020). Supply chain ambidexterity and manufacturing SME performance: The moderating roles of network capability and strategic information flow. International Journal of Production Economics, 221, 107470. doi:10.1016/j.ijpe.2019.08.005

Pauceanu, A. M., Alpenidze, O., Edu, T., \& Zaharia, R. M. (2019). What determinants influence students to start their own business? Empirical evidence from United Arab Emirates Universities. Sustainability, 11(1), 92. doi:10.3390/su11010092

Prohorovs, A., Bistrova, J., \& Ten, D. (2019). Startup Success Variables in the Capital Attraction Stage: Founders' Perspective. Journal of East-West Business, 25(1), 26-51. doi:10.1080/10669868.2018.1503211

Ringle, C. M., Wende, S., \& Becker, J. M. (2015). SmartPLS3. Bönningstedt: SmartPLS.

Seo, Y. W., \& Lee, Y. H. (2019). Effects of internal and external variables on business performance of startups in South Korea: The engine of new market dynamics. International Journal of Engineering Business Management.

Wold, H. (1985). Partial least squares. In Encyclopedia of statistical sciences. Wiley.

Yusuff, Y. Z. M., Bakar, A. A., \& Ahmad, S. (2016). Determinant Variables of Women Entrepreneurs' Business Performance: A Conceptual Framework. Journal of Global Business and Social Entrepreneurship, 1(1), 55-67. 


\section{APPENDIX I.}

\section{Characteristics of The Samples}

\section{Appendix 1. Characteristics of the samples}

\begin{tabular}{|c|c|c|c|}
\hline \multicolumn{2}{|r|}{ Characteristics of the sample } & \multirow{2}{*}{$\begin{array}{c}\text { Frequency } \\
124\end{array}$} & \multirow{2}{*}{$\frac{\text { Percent }}{60.5}$} \\
\hline & Private business & & \\
\hline & Corporate business & 81 & 39.5 \\
\hline \multirow{6}{*}{ Industry sector } & Electrics/Electronics & 38 & 18.5 \\
\hline & Machinery/Parts & 30 & 14.6 \\
\hline & IT/SW & 36 & 17.6 \\
\hline & Pore/Fiber/Material & 36 & 17.6 \\
\hline & Life/Food & 26 & 12.7 \\
\hline & Craft/others & 39 & 19 \\
\hline \multirow{5}{*}{ Founding years } & Less than a year & 15 & 7.3 \\
\hline & Less than one year to two years & 66 & 32.2 \\
\hline & Less than 2 years to3years & 66 & 32.2 \\
\hline & Less than 3years to5years & 48 & 23.4 \\
\hline & More than 5 years & 10 & 4.9 \\
\hline \multirow{5}{*}{ Sales volume } & Less than 0.1 million $\$$ & 72 & 35.1 \\
\hline & Less than 0.1 million $\$$ to 0.3 million $\$$ & 66 & 32.2 \\
\hline & 0.3 million $\$$ to less than 0.5 million $\$$ & 45 & 22 \\
\hline & Less than 0.5 million $\$$ to less than 1 million $\$$ & 19 & 9.3 \\
\hline & More than 1 million $\$$ & 3 & 1.5 \\
\hline \multirow{3}{*}{ Manufacturing method } & Outsourced & 47 & 22.9 \\
\hline & Outsourcing and self & 127 & 62 \\
\hline & Itself & 31 & 15.1 \\
\hline \multirow{4}{*}{ Employees } & Less than 3 people & 95 & 46.3 \\
\hline & 3 or more people- 5 people less than & 80 & 39 \\
\hline & 5 or more people -less than 10 people & 28 & 13.7 \\
\hline & More than 10 people & 2 & 1 \\
\hline \multirow{2}{*}{ Gender } & Male & 137 & 66.8 \\
\hline & Female & 68 & 33.2 \\
\hline \multirow{4}{*}{ Age } & $20 \mathrm{~s}$ & 18 & 8.8 \\
\hline & $30 \mathrm{~s}$ & 82 & 40 \\
\hline & $40 \mathrm{~s}$ & 79 & 38.5 \\
\hline & Over 50s & 26 & 12.7 \\
\hline
\end{tabular}


Seok-Soo Kim has been Director of Global Entrepreneurs Foundation, South Korea since 2019 and Professor at Youth Entrepreneurs Academy, South Korea. He has more than 22 years of experience working at Samsung Fine Chemicals (R\&D) and Kolon Industries (Technology Commercialization). His major research interests are SMEs' Performance, Startups \& Entrepreneurs, Technology Commercialization, Digital Transformation of SMEs, Global Entrepreneurship, SMEs'Business Management. 